\title{
Management of Teachers' Creative Activity Development
}

\author{
Gulnar Karimzhanovna Shakhazhanova \\ Nartay Kuandykovich Zhussupov \\ Mukhabbat Nurzhauovna Baratova \\ Pavlodar State University named after S. Toraigyrov, \\ 64 Lomova Street, Pavlodar, 1400o8, Kazakhstan
}

DOI: https://doi.org/10.36941/ajis-2021-0o75

\begin{abstract}
The paper justifies the management of teachers' creative activity development based on best practices described by Seit Kaskabasov. It analyzes and generalizes the theoretical positions of the modern state of the problem of teachers' creative activity development based on available psychological and pedagogical scientific research. It also contains the description of the creation and experimental testing of a creative activity development model applied to university teachers. The results of the study are recommended for practical use in universities to improve the effectiveness of the managerial qualities of the teaching staff.
\end{abstract}

Keywords: management, creative activity, teacher, activity, Seit Kaskabasov, model

\section{Introduction}

In the context of the increased formal requirements for the work of tertiary education teachers, mainly related to the documentary design of educational, methodical, and research work, the issues of professional adaptation, promotion of professional and creative growth often remain beyond the attention of the teaching staff. The issue of management of teachers' creative activity development in tertiary education is currently one of the most urgent ones, as it is closely related to the growing need of the society for active, focused individuals, adapted to the social environment and capable of productive and creative activity. The methodological approach of the research is the consideration of creativity as a social phenomenon. A systematic approach integrates components of creative activity into a system. A diagnostic approach for the development of creative activity and professional creativity of teachers and a socio-pedagogical approach in determining the conditions and the factor of training in the system of advanced training allow increasing the efficiency of development of creative activity in high school teachers.

\section{Literature Review}

The professional activities of the university teacher have been studied in the works of various fundamental scholars, such as S. Kaskabasov (2015), Marzhan Kenenbaeva, Baglan Zhaparova, Aliya 
Mombek, Akgul Zhubandykova et al. (2017), and Ali Aldhaheri (2017). Pedagogical communication has been reviewed in the works of K. M. Berkimbaev and B. T. Kerimbaeva (2012); S.V. Osipova et al. (2014) and S. Kaskabasov (2015). The formation of pedagogical skills and abilities and the proficiency of the teacher has been discussed in the works of G. O. Rakhimbekova, J. Z. Sakenov et al. (2015); Z.S. Shavalieva, D.Z. Sakenov (2013), S. Kaskabasov (2015), and G.A. Arsamerzaev et al. (2014). In recent years, several works have been published describing the modern ideas on the creative process offered by different authors (Nurgazina, Sakenov et al., 2016; Aliyevich, Sakenov et al., 2014; Mirza, 2013). Recognizing the personality-forming function of activity, E. K. Henner (2004) convincingly demonstrates that the basis of personality development in adulthood is most closely connected with the choice, collection, training, and performance of a certain type of professional activity, forming the self-determination of a professional, as well as their competence.

The analysis of specific activity components from the psychological point of view allows not only to define the set of professional requirements to the personality of the teacher but also to distinguish the social and pedagogical conditions promoting the development of the creative activity of the tertiary education teacher.

The choice of the topic of this paper was conditioned by the lack of a developed integrated approach to the problem of teachers' creative activity development in psychology and pedagogy, as well as the practical importance and relevance of the problem in the context of higher education.

As noted by S. Kaskabasov, the process of managing the teachers' creative activity development is determined by the goals and objectives of the education system, the specifics of this activity, the socio-psychological, organizational, and pedagogical conditions affecting it, and the way that the management of teachers' creative activity is organized (Kaskabasov, 2015).

Despite the importance of previous studies, there is not much data on the specific features of the management of creative activity of the tertiary education teacher, the essence of this activity, and the external and internal contradictions arising in a professional environment. The diagnosis and forecasting of the individual creative activity development process in the framework of the person's occupation require clarification. The nature of objective dependencies between the course of development of teachers' creative activity and the system of influence on their psychological and pedagogical characteristics has been traced poorly. All this testifies to insufficient development of management of the creative activity development process for tertiary education teachers.

This led to a contradiction between the need for the development of teachers' creative activity in modern tertiary education and the lack of theoretical justification and practical development of a set of conditions that would ensure the effectiveness of this process.

Considering this contradiction, the purpose of the study was chosen to identify the conditions that ensure the effectiveness of creative activity development in tertiary education teachers and improve management efficiency.

\section{Methodology}

Empirical methods were chosen as a way to develop and substantiate the model of creative activity development in university teachers by means of the ascertaining and forming stages of a pedagogical experiment aimed at the process of creative activity development in tertiary education teachers. During the experiment, we used survey methods and methods of mathematical statistics to evaluate the experiment results. Methods of qualitative and quantitative analysis of the data were chosen as a way to systematize and summarize the results of the study of the creative activity development in tertiary education teachers. The study was conducted at the Pavlodar State University named after S. Toraigyrov, where about 41 personal characteristics from the university HR department, test method results, and interviews with teachers were analyzed. The respondents participating in this study were the teachers of the aforementioned university. 41 teachers took part in the study. The selection criterion was a full-time university teacher. In the course of experimental work, it was assumed that work would be considered effective if increasing dynamics of component development were registered in the 
experimental group (EG) in course of development of the components of teachers' creative activity, and if the increase in quality in this group was higher than in the control group (CG). A CG of 20 teachers and an EG of 21 teachers were selected for experimental work. The creative activity development level in the teachers of the EG and CG was determined at the beginning and the end of experimental work.

In the course of the experimental work conducted from September 1, 2019 to June 1, 2020, it was assumed that it can be considered effective if, with the development of the components of creative activity, increasing dynamics of the development of components in the experimental group are registered and the increase in quality in this group is higher than in control. A CG of 20 teachers and an EG of 21 teachers were selected for experimental work. We determined the level of creative activity development among the teachers of the CG and EG at the beginning and the end of the experiment. Primary diagnostics of creative activity of teachers of the EG and CG were carried out before the experiment. The survey participants evaluated on a five-point scale the degree of development of the proposed elements, based on which, by calculating the simple arithmetic mean, conclusions were made about the average values of the development of individual elements, structural components, and the studied quality as a whole. The average score of self-assessment of the development of the elements (X) that make up the components of creative activity in teachers was determined based on the arithmetic mean formula:

$$
\mathrm{X}=\sum_{\mathrm{i}=1}^{\mathrm{k}} \mathrm{ni} \mathrm{Xi}
$$

Where $\mathrm{x}_{\mathrm{i}}$ is the number of points; $\mathrm{n}_{\mathrm{i}}$ is the number of answers with an indication of this point; $\mathrm{N}$ is the number of respondents.

The increase was determined using the following formula:

hi $=\mathrm{Ck}-\mathrm{Cn}$

where hi is the increase in the average score in the ith component; $\mathrm{Ck}$ is the average score of the component based on self-assessment at the end of the experiment; $\mathrm{Cn}$ is the average score of the component based on self-assessment at the beginning of the experimental work.

In the course of the study, we summarized and corrected the study materials, formulated the main scientific recommendations, and implemented them into the teaching practice.

\section{Results}

\subsection{Model construction}

The creative activity of the tertiary education teacher means the ability of the teacher to rise above the level of requirements of the professional situation, to set goals aimed at finding a new way to solve professional problems, to find new professional tasks that require creative solutions and implement them into teaching activities, as well as into the teachers' cognitive activities arising due to the need for new knowledge and skills (Kaskabasov, 2015). Based on the analysis of psychological, pedagogical, sociological literature (such as Sakenov et al., 2012; Singh, 2017; Zholdasbekov, Sakenov et al., 2018), G. Zhanzakova, T. Kenzhebayeva, Bibenur Baidalinova (2017), and the best practices described by Seit Kaskabasov (2015), we view the development of the creative activity of the tertiary education teacher as a process and a result of the promotion of human creativity in their work, motivated by the desire for positive dynamics of personal growth.

The socio-pedagogical conditions in our study will be interpreted as a set of local (existing in a particular university) factors and requirements that, if considered and implemented, provide the expected pedagogical result.

To determine the factors that influence the development of the creative activity of the tertiary education teacher, we turned to the works devoted to the study of professional evolvement, development, and achievement of professional success. Among the factors that can influence the 
professional development of a specialist the authors highlight the importance of the social environment (the objective factor) (Gorenkov, 2012), the personal characteristics of the individual (the subjective factor) (Ostrianko, 2014), and the content and nature of professional activities (Upadhyay, 2019; Simendinger et al., 2017). The essential characteristics of professional creativity were also considered, such as the presence of the necessary objective and personal background, problematic situations, social or personal significance, novelty, and originality of the process and result (Masoumi et al., 2019). According to the experience of S. Kaskabasov, it has been established that the effectiveness of teachers' creative activity development is influenced by certain conditions that depend on the teacher (internal conditions) and other conditions that depend on the environment (external conditions).

We reviewed the process of creative activity development, considering the following three factors: 1) immersion in a real educational and creative atmosphere favorable for the emergence of new ideas and opinions; 2) inclusion into the explorative and research activities to find targeted solutions to educational problems; 3 ) the level of mastery in the methods, forms, and means of teachers' creative activity development shown by the head of the university.

The generalized results of the research have been reflected in the model of creative activity development for tertiary education teachers. The model developed by us represents a combination of the goal (teachers' creative activity development in the system of retraining and advanced training), objectives, principles (variability, humanization. coordination, dialogism), conditions (individualization, problematicity, professional orientation), components (motivational, orientational, content-related and operational, value-based and volitional, evaluative), levels of development (the first level - low (replicating), the second level - medium (interpreting), the third level - sufficiently high (creative), the fourth level - high (perspective-based and creative), and the results of creative activity development in the system of retraining and advanced training (Fig. 1).

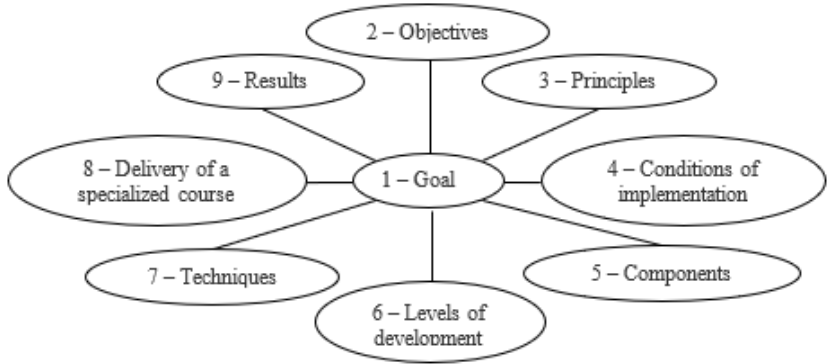

1 - Goal: To develop the creative activity of the tertiary education teacher.

2 - Objectives: to diagnose the level of teachers' creative activity development; to develop target settings for teachers' creative activity development; to provide the teachers with the necessary skills to complete the goal. 3 - Principles: variability; humanization; coordination; dialogism.

4 - Conditions of implementation: individualization, problematicity, professional orientation.

5 - Components: motivational, orientational, content-related and operational, value-based and volitional, evaluative.

6 - Levels of development (the first level - low (replicating), the second level - medium (interpreting), the third level - sufficiently high (creative), the fourth level - high (perspective-based and creative)).

7 - Techniques: educating teachers through retraining and advanced training, using a modular program consisting of separate parts of the training material (modules), principles of modular training (modularity, structuring the content of training, flexibility, efficiency, parity), teaching methods (informative (lectures, consultations, conversations); operational (individual tasks, practical work), exploratory (business game, game situations, problem tasks, design), control-related (current, intermediate and final control).

8 - Delivery of a specialized course called "Theoretical basics of creative activity development in tertiary education teachers".

9 - Results: Development of creative activity in university teachers.

Figure 1. The model of creative activity development in tertiary education teachers (based on the ideas of Seit Kaskabasov) 
Considering the structural components of the model of teachers' creative activity development in the system of training and advanced training, it can be assumed that the increase in the level of development of individual components elevates the level of development of the structure as a whole. Hypothetically, we had distinguished four levels of development of teachers' creative activity for each component.

1. The first level was defined as low (replicating). The teachers who are at this level can be distinguished by their passive attitude to the improvement of their professional activities, abstract thinking, and analytic ability, and are incapable of obtaining knowledge independently.

2. The second level can be called medium (interpretive). At this level, teachers possess cognitive abilities, show independence, are actively involved in cognitive and creative activity, but are not confident in their abilities and can be characterized by increased emotional expansiveness.

3. The third level was called sufficiently high (creative), where the cognitive capabilities and skills allow the teacher to master academic material independently. At this level, teachers are quite demanding of themselves and capable of reproducing received knowledge, make an effort to act on the level of creative abilities in new unusual situations, create study assignments and design the process of their execution.

4. The fourth level was defined as high (perspective-based and creative). At this level, teachers are aware of their cognitive capabilities and abilities, have pronounced creative independence in solving professional problems, possess developed value-based, volitional and evaluative components.

Our goal can be achieved by educating teachers in the process of retraining and advanced training, using a modular program of the special course "Theoretical Foundations of the Creative Activity Development of a Tertiary Education Teacher" consisting of separate parts of the training material (modules), principles of modular training (modularity, structuring the content of training, flexibility, efficiency, parity), training methods (informative, operational, exploratory), control methods (current, boundary and final control).

\subsection{Experimental work}

The main objectives of the experimental work were to test our model and technique of creative activity development for tertiary education teachers, to establish their substantive and methodological sides, and to check the feasibility of the implementation of this model into pedagogical practice. To address them, we developed a specialized course called "Theoretical basics of creative activity development in tertiary education teachers."

The topics of the course were supposed to be accompanied by the following types of educational work: participation in the review lecture; individual consultation; independent study of the theoretical material on the program and preparation of an answer to the individual task of its practical part. The practical classes focused on group forms of active and creative teacher training in the system of retraining and advanced training. The following advantages of group training methods were used: active involvement in the creative process and collective activities of all members of the group. The applied exploratory methods of training (business games, game situations, problem tasks, design, roleplaying games) contributed to the formation of skills and abilities of professional and creative activity in atypical situations.

The effectiveness of the developed model was confirmed by the data of self-assessment and expert evaluation of the development of the components of tertiary education teachers' creative activity in the experimental and control groups. The heads of the university (including the dean, their deputies, heads of departments) and highly qualified teachers participated in the evaluation as experts.

The results of the survey of the EG and CG are presented in Table 1. 
Table 1. Self-assessment of the development of components of teacher's creative activity in the EG and CG at the beginning of experimental work

\begin{tabular}{clcc}
\hline No. & Quality components & $\begin{array}{c}\text { Self-assessment of } \\
\text { EG teachers, average score }\end{array}$ & $\begin{array}{c}\text { Self-assessment of CG } \\
\text { teachers, average score }\end{array}$ \\
1 & Motivational & 3.11 & 3.11 \\
2 & Orientational & 2.58 & 2.59 \\
3 & Content-related and operational & 1.80 & 1.83 \\
4 & Value-based and volitional & 2.33 & 2.31 \\
5 & Evaluative & 1.76 & 1.78 \\
6 & Overall quality & 2.32 & 2.33 \\
\hline
\end{tabular}

The results of the expert evaluation at the beginning of the experiment were slightly lower than the self-assessment of teachers, which is reflected in Table 2.

Table 2. Expert evaluation of the development of components of teachers' creative activity in the EG and $C G$ at the beginning of experimental work

\begin{tabular}{clcc}
\hline No. & Quality components & $\begin{array}{c}\text { Expert evaluation of } \\
\text { EG teachers, average score }\end{array}$ & $\begin{array}{c}\text { Expert evaluation of } \\
\text { CG teachers, average score }\end{array}$ \\
1 & Motivational & 3.08 & 3.07 \\
2 & Orientational & 2.61 & 2.59 \\
3 & Content-related and operational & 1.71 & 1.68 \\
4 & Value-based and volitional & 2.35 & 2.38 \\
5 & Evaluative & 1.61 & 1.60 \\
6 & Overall quality & 2.27 & 2.25 \\
\hline
\end{tabular}

Thus, the analysis of quantitative indicators of overall quality development at the beginning of the experiment leads to the conclusion that the difference between the teachers of the EG and CG was minimal. Control measurements of the level of development of teachers' creative activity were carried out at the end of experimental work. The diagnostic results are shown in Table 3.

Table 3. Self-assessment of the development of components of teachers' creative activity in the EG and CG at the end of the experiment

\begin{tabular}{clcc}
\hline No. & Quality components & $\begin{array}{c}\text { Self-assessment of } \\
\text { EG teachers, average score }\end{array}$ & $\begin{array}{c}\text { Self-assessment of } \\
\text { CG teachers, average score }\end{array}$ \\
1 & Motivational & 4.00 & 3.18 \\
2 & Orientational & 3.97 & 2.69 \\
3 & Content-related and operational & 3.80 & 2.40 \\
4 & Value-based and volitional & 3.75 & 2.32 \\
5 & Evaluative & 3.95 & 1.86 \\
6 & Overall quality & 3.89 & 2.49 \\
\hline
\end{tabular}

The data of Table 3 show that during the experiment the level of development of the studied quality increased significantly in the EG and only slightly in the CG. At the same time, $63.3 \%$ of the teachers of the EG considered that they had reached a high level of overall quality development, and $36.7 \%$ of participants noted that they had reached the highest possible level. According to the experts, the results of the survey for the CG of teachers practically coincided with the data shown in Table 3, and for the EG with the data given in Table 4. Further, to compare the data before and after the experiment, the increase in the average score of self-assessment of the development level of teachers' creative activity in the CG and EG was evaluated (Table 5). 
Table 4. Expert evaluation of the development of components of teachers' creative activity at the end of the experiment

\begin{tabular}{clcc}
\hline \multirow{2}{*}{ No. } & Quality components & $\begin{array}{c}\text { Expert evaluation of } \\
\text { EG teachers, average score }\end{array}$ & $\begin{array}{c}\text { Expert evaluation of } \\
\text { CG teachers, average score }\end{array}$ \\
1 & Motivational & 3.87 & 3.18 \\
2 & Orientational & 3.91 & 2.73 \\
3 & Content-related and operational & 3.75 & 2.40 \\
4 & Value-based and volitional & 3.60 & 2.36 \\
5 & Evaluative & 3.90 & 1.86 \\
6 & Overall quality & 3.81 & 2.51 \\
\hline
\end{tabular}

Table 5. Increase in the average level of development of components of teachers' creative activity in the EG and CG

\begin{tabular}{clcc}
\hline No. & Quality components & $\begin{array}{c}\text { Increase in EG, } \\
\text { average score }\end{array}$ & $\begin{array}{c}\text { Increase in CG, } \\
\text { average score }\end{array}$ \\
1 & Motivational & 0.88 & 0.06 \\
2 & Orientational & 1.39 & 0.10 \\
3 & Content-related and operational & 1.40 & 0.03 \\
4 & Value-based and volitional & 1.42 & 0.01 \\
5 & Evaluative & 2.19 & 0.08 \\
6 & Overall quality & 1.46 & 0.06 \\
\hline
\end{tabular}

Table 6 shows that the increase in the average values of structural components of teachers' creative activity in the CG varies in the range from o.o1 to o.1 points. The greatest increase was observed in the orientational component, which can be explained by the constant employment of teachers in professional activities throughout the experiment. The increase in the EG of teachers varied in the range from 0.88 to 2.19 points. The evaluative component was affected the most, due to the special work with this group of teachers. The positive results of the experimental work carried out to test the model developed by us, which integrates the components and diagnostics of the development of creative activity, characteristics of professional creativity of teachers, socio-pedagogical conditions, and the learning factor in the system of training into a complex system, allow us to conclude that the identified complex of socio-pedagogical conditions contributes to the effectiveness of the development of the creative activity of the tertiary education teacher.

\section{Discussion}

Thus, unlike the studies carried out by Rakhimbekova, Sakenov et al. (2015), Zholdasbekov, Sakenov et al. (2018), Upadhyay and Paul (2019), Mirza (2013), A.S. Zhumasheva, F.T. Sametova (2014), A.A. Zholdasbekov, N. Kolyeva (2019), T.B. Kenzhebayeva (2014), we proved that the development of the creative activity of higher school teachers is an interrelated, interdependent, gradual qualitative transformation of its structural components (motivational, orientation, content-operational, valuevolitional and evaluation).

We proposed a set of socio-pedagogical conditions that ensure the effectiveness of creative activity development in tertiary education teachers and can be formed in course of the conscious efforts of the head of the university (faculty, department) and teachers in the following areas:

1) diagnostics of development features of teachers' creative activity and identification of several problems connected with these features;

2) formation of a special developing environment in the team (department, faculty, university);

3) elimination of barriers that reduce the effectiveness of the development of teachers' creative activity; 
4) special design of training sessions with a focus on the development of the components of the creative activity structure (motivational, orientational, content-related and operational, value-based and volitional, evaluative) in the process of professional development of tertiary education teachers;

5) increase in the social prestige of the teaching profession.

\section{Conclusion}

Summarizing the results of the study, the following conclusions can be drawn:

- A prerequisite for the creative activity of a teacher is hard brainwork, search, collection, and processing of information.

- The components of the creative activity of a tertiary education teacher are as follows: motivational (needs, interests, motives, emotions), orientational (adoption by the teacher of the goal of creative activity), content-related, and operational (the presence of a system of leading knowledge and methods for obtaining and processing information), value-based and volitional (desire to achieve the goal), and evaluative (a systematic receipt of the information on the course of the action taken by comparing the results with the original task).

The socio-pedagogical conditions that increase the efficiency of teachers' creative activity in tertiary education include the following:

- conscious effort of heads of the higher education institution aimed at the development of teachers' creative activity;

- diagnostics of personal features of teachers' creative activity development as a condition of individualization of the educational process in the system of professional development;

- construction of goals and objectives of professional activities, adequate to the interests, mental and physical capabilities, personal and social development of each tertiary education teacher;

- complex use of individual, group, and collective forms of interaction between teachers in pedagogical activities;

- stimulation of teachers' independence, adequate to the level of development of their creative activity;

- establishing subject-to-subject relations in the team between teachers and managers, ensuring respect for the individual, their values, opinions, the choice of creative and active solutions;

- $\quad$ systematic analysis and moral evaluation of the results and motives of conduct and practical actions of each member of the teaching staff, performed by the head of the department or institution and other teachers;

- organization of a set of activities to increase the teachers' motivation in their work, including its prestige and financial interest of university teachers;

- simulation of problem tasks and situations, external and internal prerequisites similar to the real conditions arising in professional activities and requiring an independent choice of volitional decisions, actions, creative activity during training sessions;

- coordination of educational impacts on university teachers;

- organization of individual and collective professional activities of university teachers corresponding to the needs of the society and useful for the university teaching staff;

- improving the system of professional development of tertiary education teachers by focusing the educational process on the development of components of the creative activity of the individual.

The model that was developed based on the discovered complex of socio-pedagogical conditions of creative activity development in tertiary education teachers should integrate into a complex system such components as the pedagogical goal (development of the creative activity of the teacher), objectives, essential characteristics, and social features of professional creativity which are reflected in 
the defining principle and conditions of implementation of the model, components of teachers' creative activity, levels of creative activity development and training in the system of professional development of teachers, based on a modular program.

In further research, we see it fit to focus on the definition of psychological and pedagogical mechanisms of design and management of the process of creative activity development in university teachers. The prospect of studying an individual approach to creative activity development in tertiary education teachers as a means of overcoming emotional tension is of particular importance. We connect the prospects of our further research with the solution to these and other problems.

\section{References}

Aldhaheri, A. (2017). Cultural intelligence and leadership style in the education sector. International Journal of Educational Management, 31(6), pp. 718-735. https://doi.org/10.1108/IJEM-05-2016-0093.

Arsamerzaev, G. A., Dauletova, I. G., Sakenov, J. Z. \& Toktarbayev, D. G.-S. (2014). Formation of professional competence at students (on the example of creative pedagogical specialties). Life Science Journal, 11(6s), 97-101.

Berkimbaev, K. M. \& Kerimbaeva, B. T. (2012). Communicative competence of future specialist. European Science and Technology. Proceedings of the 2th International Research and Practice Conference 9-1o May (issue Vol. 3). Bildungszentrum Rodnik e.V Wiesbaden, Germany.

Gorenkov, E. M. (2012). Innovative potential as a complete social and pedagogical system. Moscow: Prometheus publishing house.

Henner, E. K. (2004). Information and Communication Competence of the Teacher: The Structure, Requirements and Measurement System. Computer Science and Education, 12, 5-9.

Kaskabasov, S. (2015). Sobranie sochinenii. Collected works. Astana: Foliant.

Kenzhebayeva, T. B., Turganbayeva, B. Z., Mukhmetova, R. Z., Kariyev, D. D. \& Baisalbayeva, Z. S. (2014). Future teachers intellectual and creative potential development. Life Science Journal, 11(1), 321-324.

Masoumi, D., Hatami, J. \& Pourkaremi, J. (2019). Continuing professional development: policies, practices and future directions. International Journal of Educational Management, 33(1), 98-111. https://doi.org/10.1108/IJEM-032018-0109.

Mirza, N. V. (2013). Creative Component of Professional Competence of a Teacher. International Journal of Applied and Fundamental Study, 2. Retrieved from www.science-sd.com/455-24286.

Kenenbaeva, M., Zhaparova, B., Mombek, A., Iskakova, A., Meterbaeva, K., Zhubandykova, A. \& Nabuova, R. (2017). The modern methodology of shaping professional competence among university students. Man In India, 97(6), 261-273.

Nurgazina, A. B., Rakhimzhanov, K. H., Akosheva, M. K., Ibraeva, Z. B., Shaikova, G. K., Zhussupov, N. K., Baratova, M. N. \& Sakenov, J. Zh. (2016). About the Poetic Text and a Concept as Ways of Representation of Author's Subjectivity and Modality. International Journal of Environmental \& Science Education, 11(18), 11757-11770.

Osipova, S. V., Botalova, O. B., Kunanbaeva, M. S. \& Vedilina, E. A. (2014). Interaction of teachers and students as a condition of self-development of students in educational institution. Life Science Journal, 11(7s), 234-237.

Ostrianko, T. S. (2014). Mental mapping in the organizational and pedagogical activity of a secondary school social pedagogue. Modern pedagogy, 2. Retrieved from http://pedagogika.snauka.ru/en/2014/02/2069 .

Rakhimbekova, G. O., Baigozhina, Z. M., Abdrakhmanova, A. Y., Samatanova, A. R., Orazakova, R. K., Nurtayeva, Z. Z. \& Sakenov, J. Z. (2015). Development of Professional Competence in Students of Creative Pedagogical Specialties (Professionally-Oriented Aspect). Life Science Journal, 12(1s), 24-28.

Sakenov, D. Zh., Kushnir. Y. V., Shnaider, Y. \& Abdulkhamidova, D. Zh. (2012). Preparation of Students of Higher Education Institution for Professional Activity in the Course of Studying of Pedagogical Disciplines. World Applied Sciences Journal, 19(10), 1431-1436.

Sanjay, K. S. (2017) Education management in the Middle East, International Journal of Educational Management, 31(6), pp. 694-695. https://doi.org/10.1108/IJEM-o6-2017-0148.

Shavalieva, Z. S., Ahmuldinova, A. N., Isinbayeva, K. G., Ayapbergenova, G. S., Alibayeva, Z. E. \& Sakenov, D. Z. (2013). Improvement of quality of vocational training of students (based on courses of humanitarian and ecological cycles). Life Science Journal, 10, 838-841.

Simendinger, E., El-Kassar, A.-N., Gonzalez-Perez, M. A., Crawford, J., Thomason, S., Reynet, P., Kjellander, B. \& Edwards, J. (2017). Teaching effectiveness attributes in business schools. International Journal of Educational Management, 31(6), 780-80o. https://doi.org/10.1108/IJEM-05-2016-0108 
Upadhyay, P. \& Paul, M. (2019). The linkage between knowledge management practices and organization based projects for better learning outcome: A conceptual framework. International Journal of Educational Management, 33(1), 166-178. https://doi.org/10.1108/IJEM-04-2018-0133

Zhanzakova, G., Baiseitova, Zh., Kenzhebayeva, T., Murzatayeva, A., Kenenbaeva, Zhaparova, B. M., Tleulesova, A., Abdyrova, A., Karimova, R. \& Baidalinova, B. (2017). The problem of professional competence formation of future teachers in regard to development of cognitive activity of school children. WALIA Journal 33(1), 8-13

Zholdasbekov, A. A., Aymenov, M. Z., Shagataeva, Z. E., Esimkhanova, N. A., Dzhartybaeva, J. D. \& Kolyeva, N. (2019). Formation of entrepreneurial competence in students majoring in pedagogy. Revista Espacios, 40(31), 12. Retrieved from https://www.revistaespacios.com/a19v4on31/a19v4on31p12.pdf

Zholdasbekov, A. A., Zholdasbekova, B. A., Abitiarova, A. A., Sakenov, J. Z. \& Ahmuldinova, A. (2018). Pedagogical technologies for the formation of healthy lifestyle of students. Revista Espacios, 39(21), 37. Retrieved from http://www.revistaespacios.com/a18v39n21/a18v39n21p37.pdf

Zhumasheva, A. S., Sametova, F. T., Muktarova, E., Batyrkhan, B. S. \& Sultaniyazova, I.S. (2014). About a lingvocultural interference in the conditions of dialogue between cultures. Life Science Journal, 11, 360-364. 